\title{
Statistical Optimization of Medium Components of Xylanase Production by Irpex lacteus BAFC 1168 strain F under liquid fermentation
}

\author{
G. V. Díaz ${ }^{1}$, E. M. Giorgio ${ }^{1}$, M. I. Fonseca ${ }^{1}$, L. L. Villalba ${ }^{1}$, P. D. Zapata ${ }^{1}$
}

${ }^{1}$ Laboratorio de Biotecnología Molecular, Instituto de Biotecnología de Misiones (InBioMis), Facultad de Ciencias Exactas, Químicas y Naturales, Universidad Nacional de Misiones. RutaNacional12, km 7.5.Posadas, Misiones,

\section{ABSTRACT} Argentina.

The enhanced xylanase production of white rot fungus Irpex lacteus BAFC 1168 strain $\mathrm{F}$ using a liquid fermentation culture was investigated. The media nutrients were screened by a Plackett-Burman design and from the analysis of variance, carboxy-methylcellulose, urea and peptone were found to be the most positive and significant nutrient components. Hence, these three variables were selected for further optimization using a five-level central composite design in response surface methodology. The validation of the model experiment was conducted reaching $8.29 \mathrm{U} / \mathrm{mL}$ of xylanase activity when the composition medium was $1.6 \mathrm{~g} / \mathrm{L}$ of CMC, $0.84 \mathrm{~g} / \mathrm{L}$ of urea and $2 \mathrm{~g} / \mathrm{L}$ of peptone. Optimum temperature and $\mathrm{pH}$ conditions on xylanase activity were also determined using a central composite design. It was reached a maximum xylanase activity of $8.36 \mathrm{U} / \mathrm{mL}$ when temperature and $\mathrm{pH}$ were $42.8^{\circ} \mathrm{C}$ and 5.6 , respectively.

\section{Indexing terms/Keywords}

Xylanases, Irpex lacteus, white rot fungi, response surface methodology (RSM).

\section{Academic Discipline And Sub-Disciplines}

Biotechnology.

\section{SUBJECT CLASSIFICATION}

Microbiology.

\section{TYPE (METHOD/APPROACH)}

Quasi-Experimental.

\section{Council for Innovative Research}

Peer Review Research Publishing System

\section{Journal: JOURNAL OF ADVANCES IN BIOTECHNOLOGY}

Vol .5, No. 1

www.cirjbt.org , jbteditor@gmail.com 


\section{INTRODUCTION}

Hemicellulolytic microorganisms play a significant role in nature by recycling hemicellulose, one of the main components of plant polysaccharides. Xylanases (1,4- $\beta$-D-xylan-xylanhidrolases, EC 3.2.1.8.) are hemicellulolytic enzymes which randomly cleave the 1,4- $\beta$-D-xylosidic linkages in xylan, the major constituent of hemicellulose [1, 2].Xylanases derived from microorganisms have immense potential applications in textile, food, feed, paper pulp and biofuel industries due to their wide distribution, high specificity, negligible substrate loss and side product generation [3-5]. The application of xylanases in industrial and environmental technologies requires significant amounts of these enzymes at low cost [6, 7]. Therefore, the optimization of the fermentation medium culture and the search for fungi with outstanding enzyme activity are the keys of basic research for an efficient technology of enzyme production [6-8]. Although there is an extensive literature about optimization of xylanases by Ascomycetes [7, 9-11] there are still relatively little data concerning to white rot Basidiomycetes.

In this context, Misiones rainforest (Northeast of Argentina) provides an idyllic substrate for white rot fungi (WRF) due it has one of the highest biodiversity attribute of Argentina [12], representing an untapped source of new productive genotypes, interesting from both a basic and an applied viewpoint. The aim of this work was to optimize xylanase production of a white rot fungus native from Misiones, I. lacteus BAFC 1168 strain F, using statistically designed experiments. We focused our attention on developing a low-cost medium that would allow enhanced xylanase activity, using firstly a Plackett-Burman design (PBD) [13] to identify the significant medium components and then a central composite design (CCD) [14] to optimize these variables.

\section{MATERIALS AND METHODS}

\subsection{Microorganism}

The microorganism used in this study was the white rot fungus $I$. lacteus BAFC 1168 strain F and was provided by the Culture Collection of the Faculty of Forestry Sciences, National University of Misiones, Argentina.This strain was maintained and periodically sub-cultured on malt extract agar (MEA) medium ( $20 \mathrm{~g} / \mathrm{L}$ agar, $12.7 \mathrm{~g} / \mathrm{L}$ malt extract) at $4 \pm$ $1^{\circ} \mathrm{C}$. I. lacteus BAFC 1168 strain $\mathrm{F}$ was grown on MEA petri plates for $5-7$ days at $29 \pm 1^{\circ} \mathrm{C}$. One agar plug $\left(36 \mathrm{~mm}^{2}\right)$ from these petri plates covered with mycelium was inoculated into culture mediums corresponding to PBD and CCD experiments.

\subsection{Culture conditions}

Xylanase production was carried out in $250 \mathrm{~mL}$-Erlenmeyer flasks containing $30 \mathrm{~mL}$ media as according to PBD and CCD treatments. The $\mathrm{pH}$ was adjusted to 4.8 before autoclaving at $121^{\circ} \mathrm{C}$ for $20 \mathrm{~min}$. The basic medium used in PlackettBurman experiments was composed of $(\mathrm{g} / \mathrm{L}) 2.0 \mathrm{NaNO}_{3}, 1.0 \mathrm{KH}_{2} \mathrm{PO}_{4}, 0.5 \mathrm{KCl}, 0.5 \mathrm{MgSO}_{4} .7 \mathrm{H}_{2} \mathrm{O}, 0.01 \mathrm{FeSO} 4 . \mathrm{H}_{2} \mathrm{O}$ and basic medium used in central composite design was composed of $(\mathrm{g} / \mathrm{L}) 2.0 \mathrm{NaNO}_{3}, 1.0 \mathrm{KH}_{2} \mathrm{PO}_{4}, 0.5 \mathrm{KCl}, 0.5$ $\mathrm{MgSO}_{4} .7 \mathrm{H}_{2} \mathrm{O}, 0.01 \mathrm{FeSO}_{4} . \mathrm{H}_{2} \mathrm{O}, 10.0$ xylose and $1.0\left(\mathrm{NH}_{4}\right)_{2} \mathrm{SO}_{4}$. The inoculated flasks were incubated at $29^{\circ} \mathrm{C}$ for 12 days in static conditions. The broth was centrifuged at $10,000 \times \mathrm{g}$ for $10 \mathrm{~min}$ at $4^{\circ} \mathrm{C}$, and the supernatants were used for xylanase determination.

\subsection{Enzyme activity assay}

Xylanase activity assay was performed according to Bailey et al. [15]. The reaction mixture consisting in $0.1 \mathrm{~mL}$ of a $1 \%$ (w/v) suspension of beechwood xylan (Sigma-Aldrich, USA) in $50 \mathrm{mM}$ sodium acetate buffer $\mathrm{pH} 4.8$ and $0.1 \mathrm{~mL}$ of enzyme dilution (in $50 \mathrm{mM}$ sodium acetate buffer $\mathrm{pH} 4.8$ ) was incubated at $50^{\circ} \mathrm{C}$ during $60 \mathrm{~min}$. Released reducing sugars were determined by 3,5-dinitrosalicylic acid reagent (DNS) method [16]. Absorbance was measured at $540 \mathrm{~nm}$ in a Shimadzu UV- 3600 spectrophotometer. The enzyme activities were expressed as international units (U), defined as the amount of enzyme needed to produce $1 \mu \mathrm{mol}$ of reducing sugar per min at $50^{\circ} \mathrm{C}$.

\subsection{Screening of media components using a PBD}

A 20-runs PBD was used to select significant medium components affecting xylanase production by $\mathrm{I}$. lacteus BAFC 1168 strain $F$. A total of thirteen variables were screened including six carbon sources: lactose $\left(X_{1}\right)$, glucose $\left(X_{2}\right)$, xylose $\left(X_{3}\right)$, xylan $\left(X_{4}\right)$, carboxy-methylcellulose $\left(C M C, X_{5}\right)$ and crystalline cellulose $\left(C C, X_{6}\right)$ at 0 and $10 \mathrm{~g} / \mathrm{L}$ as $(-)$ and $(+)$ level, respectively; three nitrogen sources: urea $\left(\mathrm{X}_{8}\right)$, peptone $\left(\mathrm{X}_{9}\right),\left(\mathrm{NH}_{4}\right)_{2} \mathrm{SO}_{4}\left(\mathrm{X}_{10}\right)$ at 0 and $1 \mathrm{~g} / \mathrm{L}$ as $(-)$ and $(+)$ level , and a surfactant Tween $20\left(X_{12}\right)$ at 0 and $1 \mathrm{~mL} / \mathrm{L}$ as $(-)$ and $(+)$ level, respectively. Three dummy variables $\left(X_{7}, X_{11}\right.$ and $\left.X_{13}\right)$ were also included to estimate interactive effects not detected in the analysis of the design [17]. The main effect was calculated as the difference between the average of measurements at the high level settings $(+)$ and the average of measurements at low level setting (-) of each factor. Experimental PBD was based on the first order model:

$$
Y=\beta_{0}+\sum \beta_{i} X_{i}
$$

where $Y$ is the response (xylanase production, $U / \mathrm{mL}$ ), $\beta_{0}$ is the model intercept, and $\beta_{i}$ is the linear coefficient and $X_{i}$ is the level of independent variable. All experiments were carried out in duplicate and the average of xylanase activities were considered as the response. Experimental results were analyzed using the statistical software package Statgraphics Centurion XVI.I. 


\subsection{Optimization of significant variables using response surface methodology (RSM)}

Once the critical factors were identified through the PBD, a CCD was used to investigate the optimum concentration and to study the interactions of the three most positive significant factors, namely CMC, urea and peptone. Each variable was studied at five different levels: $[-\alpha(-1.68)$ and $+\alpha(+1.68)$, axial points]; $(-1$ and +1 , factorial points), and the central coded value of zero (Table 1).

Table 1.Range of variables at different levels for the central composite design for $\mathrm{CMC}$, urea and peptone.

\begin{tabular}{|c|c|c|c|}
\hline \multirow{2}{*}{$\begin{array}{c}\text { Coded value } \\
\qquad x_{i}\end{array}$} & \multicolumn{3}{|c|}{ Independent variables $X_{i}(\mathrm{~g} / \mathrm{L})$} \\
\hline & CMC $(i=1)$ & Urea $(i=2)$ & Peptone $(i=3)$ \\
\hline-1.68 & 1.60 & 0.32 & 0.32 \\
\hline-1 & 5 & 1.00 & 1.00 \\
\hline 0 & 10 & 2.00 & 2.00 \\
\hline 1 & 15 & 3.00 & 3.00 \\
\hline 1.68 & 18.40 & 3.68 & 3.68 \\
\hline
\end{tabular}

A total of 20 experimental runs performed in duplicate including 6 central points were used to optimize the chosen key factors for achieving maximum xylanase production. The average from replicated values of xylanase activity was taken as dependent variable or response $Y$. For the response surfaces, the experimental data were fitted to a second order polynomial equation of the form:

$$
Y=\beta_{0}+\sum \beta_{i} X_{i}+\sum \beta_{i i} X_{i}^{2}+\sum \beta_{i j} X_{i} X_{j}
$$

where $Y$ is the measured response (xylanase production, $\mathrm{U} / \mathrm{mL}$ ), $\beta_{0}$ is the model constant, $\beta_{i}$ is the linear coefficient, $\beta_{i i}$ is the quadratic coefficient, $\beta_{i j}$ is the interaction coefficient, $X_{i}$ and $X_{j}$ are coded independent variables, subscripts iand $j$ takes values from 1 to the number of variables.

Statgraphics Centurion XVI.I software was used in the experimentaldesign, quadratic model building and data analysis. The optimal levels of the variables were obtained by solving the regression equation and by analyzing the response surface plots using the same software.

\subsection{Optimum temperature and $\mathrm{pH}$}

To select the optimum conditions of temperature and $\mathrm{pH}$ for xylanase activity, supernatants from CCD run $\mathrm{N}^{\circ} 13$ was used in a new five level CCD. A total of twelve experimental runs, including 4 central points, were performed to study the effects of temperature and $\mathrm{pH}$ at different levels on xylanase activity.For experimental design and data analysis were used the Statgraphics Centurion XVI.I software.The temperatures used were $29,35,50,65$ and $72^{\circ} \mathrm{C}$ and the following buffers were used: citrate-phosphate $0.1 \mathrm{M}$ for $\mathrm{pH} 3.39$ and 3.8 , sodium acetate $0.1 \mathrm{M}$ for $\mathrm{pH} 4.8$ and phosphate acetate $0.1 \mathrm{M}$ for $\mathrm{pH} 5.8$ and 6.2 .

\section{RESULTS AND DISCUSSION}

\subsection{Screening of media components using a PBD}

The experimental matrix of the design and the responses obtained for each trial is shown in Table 2, revealing a wide variation according to the process conditions used (from 0.00 to $0.87 \mathrm{U} / \mathrm{mL}$ ). Among these, the highest xylanase activity was obtained in experiment trial $\mathrm{N}^{\circ} 18$, followed by the trials 9,10 , and 6 . The multiple regression analysis revealed a $R^{2}$ of 0.93 , indicating that the model represents the data adequately. 
Table 2. Experimental design and results for the Plackett-Burman design.

\begin{tabular}{|c|c|c|c|c|c|c|c|c|c|c|c|c|c|c|}
\hline \multirow{2}{*}{ Runs } & \multicolumn{13}{|c|}{ Coded levels } & \multirow{2}{*}{$\begin{array}{c}\text { Xylanase Activity } \\
\text { (U/mL) }\end{array}$} \\
\hline & $\mathrm{X}_{1}$ & $\mathbf{X}_{2}$ & $\mathbf{X}_{3}$ & $X_{4}$ & $X_{5}$ & $X_{6}$ & $\mathbf{X}_{7}$ & $\mathrm{X}_{8}$ & $X_{9}$ & $X_{10}$ & $X_{11}$ & $X_{12}$ & $X_{13}$ & \\
\hline 1 & + & - & - & - & - & + & - & + & - & + & + & + & + & 0 \\
\hline 2 & - & + & + & - & + & + & - & - & - & - & + & - & + & 0 \\
\hline 3 & - & + & + & - & - & - & - & + & - & + & - & + & + & 0 \\
\hline 4 & - & - & - & - & + & - & + & - & + & + & + & + & - & 0.373 \\
\hline 5 & - & - & - & - & - & - & - & - & - & - & - & - & - & 0 \\
\hline 6 & + & + & + & - & - & + & + & - & + & + & - & - & - & 0.319 \\
\hline 7 & - & - & + & + & - & + & + & - & - & - & - & + & - & 0 \\
\hline 8 & - & + & - & + & + & + & + & - & - & + & + & - & + & 0.208 \\
\hline 9 & - & + & - & + & - & + & + & + & + & - & - & + & + & 0.617 \\
\hline 10 & + & + & - & - & + & + & - & + & + & - & - & - & - & 0.759 \\
\hline 11 & + & - & + & + & + & + & - & - & + & + & - & + & + & 0.503 \\
\hline 12 & + & + & + & + & - & - & + & + & - & + & + & - & - & 0 \\
\hline 13 & + & - & + & - & + & + & + & + & - & - & + & + & - & 0 \\
\hline 14 & - & - & - & + & - & + & - & + & + & + & + & - & - & 0.464 \\
\hline 15 & + & - & + & + & - & - & - & - & + & - & + & - & + & 0.179 \\
\hline 16 & + & + & - & - & - & - & + & - & + & - & + & + & + & 0.254 \\
\hline 17 & - & + & + & + & + & - & - & + & + & - & + & + & - & 0.640 \\
\hline 18 & - & - & + & - & + & - & + & + & + & + & - & - & + & 0.876 \\
\hline 19 & + & + & - & + & + & - & - & - & - & + & - & + & - & 0 \\
\hline 20 & + & - & - & + & + & - & + & + & - & - & - & - & + & 0 \\
\hline
\end{tabular}

Table 3 details the analysis of variance for xylanase production and shows the rank of significance of the factors. $P$ values less than 0.05 (> 95\% confidence level) indicate that the model terms were statistically significant.

Table 3. Results of the regression analysis of the Plackett-Burman design for xylanase production.

\begin{tabular}{|cccccc|}
\hline Variable & Effect & F-Ratio & p-value & Ranking \\
\hline$X_{1}$ & -58.20 & 14.68 & 0.0007 & 4 \\
$X_{2}$ & 20.03 & 1.74 & 0.1989 & 8 \\
$X_{3}$ & -7.99 & 0.28 & 0.6034 & 10 \\
$X_{4}$ & 1.45 & 0.01 & 0.9244 & 13 \\
$X_{5}$ & 76.22 & 25.27 & 0.0000 & 3 \\
$X_{6}$ & 27.43 & 3.26 & 0.0825 & 6 \\
$X_{7}$ & 5.16 & 0.12 & 0.7369 & 11 \\
$X_{8}$ & 75.96 & 25.00 & 0.0000 & 2 \\
$X_{9}$ & 238.79 & 247.04 & 0.0000 & 1 \\
$X_{10}$ & 14.79 & 0.95 & 0.3393 & 9 \\
$X_{11}$ & -47.78 & 9.89 & 0.0041 & 5 \\
$X_{12}$ & -20.93 & 1.90 & 0.1801 & 7 \\
$X_{13}$ & 4.10 & 0.07 & 0.7893 & 12 \\
\hline
\end{tabular}


$\mathrm{X}_{1}$ : Lactose; $\mathrm{X}_{2}$ : Glucose; $\mathrm{X}_{3}$ : Xylose; $\mathrm{X}_{4}$ : Xylan; $\mathrm{X}_{5}$ : carboxymethylcellulose $(\mathrm{CMC}) ; \mathrm{X}_{6}$ : cellulose crystalline $(\mathrm{CC})$; $\mathrm{X}_{7}$ : false variable I (FVI); $\mathrm{X}_{8}$ : peptone; $\mathrm{X}_{9}$ : urea; $\mathrm{X}_{10}$ : $\left(\mathrm{NH}_{4}\right)_{2} \mathrm{SO}_{4} ; \mathrm{X}_{11}$ : false variable II (FVII); $\mathrm{X}_{12}$ : tween $20 ; \mathrm{X}_{13}$ : false variable III (FVIII).

Pareto chart illustrates the effects of the experimental factors on xylanase production (Fig. 1).

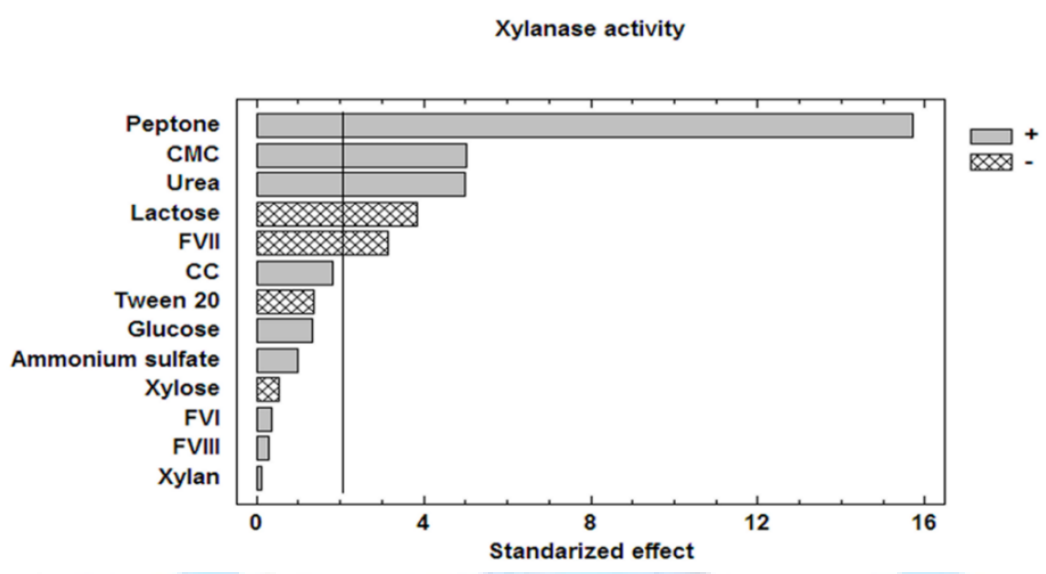

Figure 1. Pareto chart for xylanase production by I. lacteus BAFC 1168 strain F. CMC: carboxymethylcellulose;

CC: cellulose crystalline; FVI, FVII and FVIII: dummy variables. Bars extending beyond the vertical line correnspond to effects statistically significant at $95 \%$ confidence level.

Two of the three nitrogen sources, peptone and urea, had significant positive effects on xylanase production, indicating an increase of enzyme activity when the variables levels were the higher. Regarding to carbon sources, in this study, CMC showed statistical significant and positive effect on xylanase production by I. lacteus BAFC 1168 strain F. In contrast, lactose and FVII had significant and negative effect on enzyme production; therefore these variables were no longer taken into account, while the positive factors were included in the next CCD optimization. The other variables, CC, Tween 20 , glucose, ammonium sulfate, xylose and xylan had no significant effects on xylanase production.

\subsection{Optimization of significant variables using RSM}

Different concentrations of the selected nutrients, CMC, urea and peptone were tested to optimize them using a RSM. A rotary CCD design with 20 experiments was carried out and the responses are given in Table 4.

Table 4. Experimental design and results of the central composite design for CMC, urea and peptone.

\begin{tabular}{|ccccc|}
\hline Run & CMC & Urea & Peptone & Xylanase Activity U/mL) \\
\hline 1 & 0 & 0 & 0 & 0.942 \\
2 & 0 & 0 & 0 & 0.921 \\
3 & -1 & -1 & -1 & 0.604 \\
4 & 0 & 0 & -1.68 & 0.088 \\
5 & 1 & -1 & 1 & 1.288 \\
6 & -1 & 1 & 1 & 0.598 \\
7 & 1 & 1 & -1 & 0.244 \\
8 & 0 & 0 & 0 & 1.057 \\
9 & 0 & 1.68 & 0 & 0.215 \\
10 & 1 & -1 & -1 & 0.00 \\
11 & 0 & 0 & 0 & 0.885 \\
12 & 1.68 & 0 & 0 & 1.224 \\
13 & -1.68 & 0 & 0 & 7.041 \\
14 & -1 & -1 & 1 & 1.588 \\
15 & 0 & 0 & 0 & 0.797 \\
16 & 1 & 1 & 1 & 1.296 \\
17 & -1 & 1 & -1 & 0.096 \\
18 & 0 & 0 & 0 & 0.928 \\
19 & 0 & -1.68 & 0 & 1.508 \\
20 & 0 & 0 & 1.68 & 1.412 \\
\hline
\end{tabular}


It can be seen considerable variation in xylanase production depending upon the medium composition, where the maximal xylanase activity reached was $7.04 \mathrm{U} / \mathrm{mL}$ in the experiment $\mathrm{N}^{\circ} 13$ with $1.6 \mathrm{~g} / \mathrm{L}$ of CMC, $2 \mathrm{~g} / \mathrm{L}$ of urea and $2 \mathrm{~g} / \mathrm{L}$ of peptone.

To explain the effect of the levels of $\mathrm{CMC}$, urea and peptone on xylanase production, the results obtained from the CCD were fitted to a second order polynomial equation [Eq. (3)]:

$\mathrm{Y}=964.175-710.179(\mathrm{CMC})-245.196$ (urea) +461.984 (peptone) $+875.06(\mathrm{CMC})^{2}$

$+217.498(\mathrm{CMC})$ (urea) + $106.505(\mathrm{CMC})$ (peptone) -286.327 (urea) ${ }^{2}$

-84.76 (urea) (peptone) - 341.192 (peptone) $^{2}$

where $\mathrm{Y}$ is the predicted response of xylanase production.

The statistical significance of the regression model and the analysis of variance for xylanase production are shown in Table 5.

Table 5.Results of the regression analysis of the central composite design for CMC, urea and peptone on xylanase production.

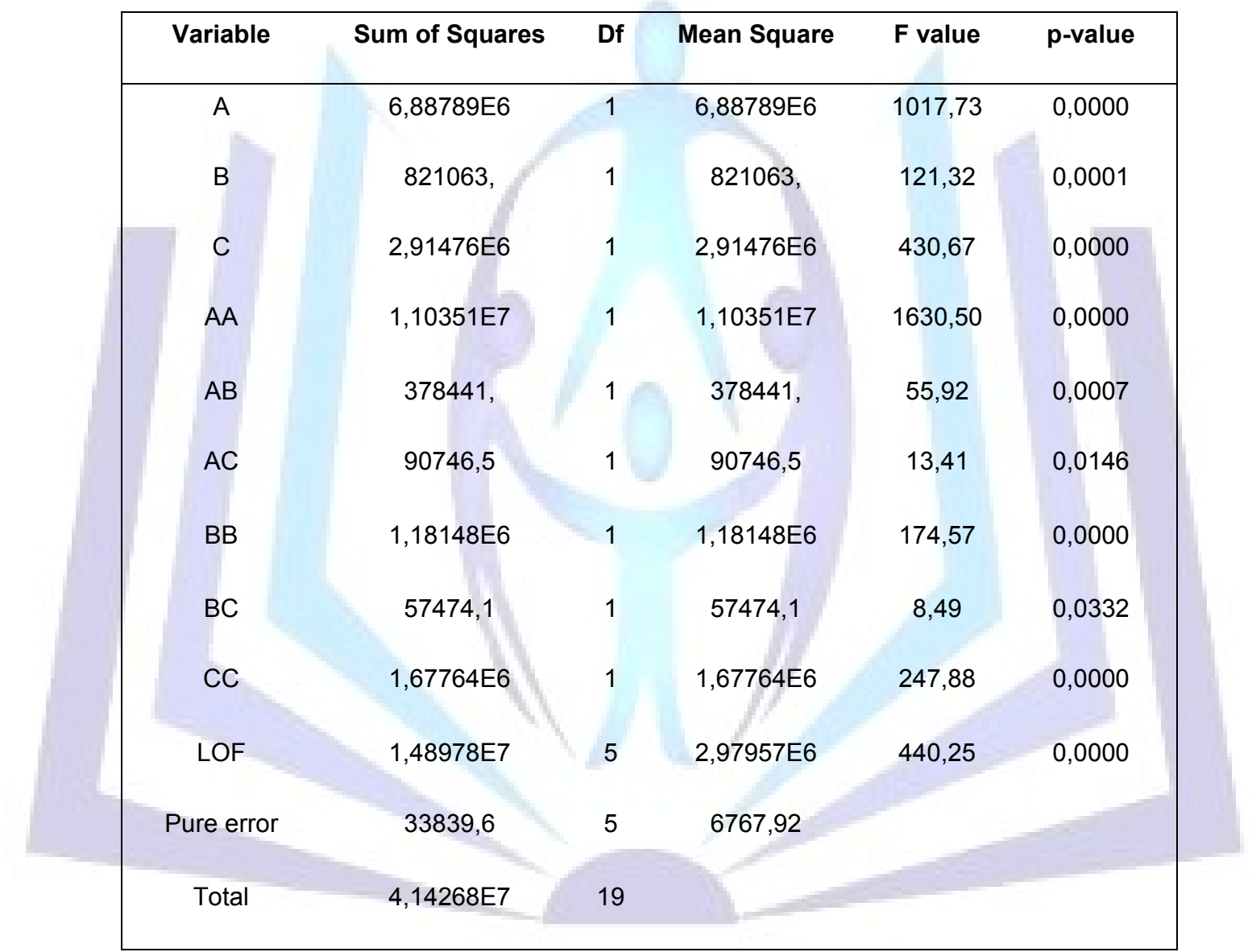

A: carboxymethylcellulose (CMC); B: urea; C: peptone; LOF: lack of fit; df: degree of freedom

Linear, quadratic and cross terms were all statistically significant and the relationship between the response and the experimental data is illustrated in Fig. 2. Fig. 2A describes the effects of CMC and urea on xylanase production when peptone was fixed at its middle level $(2 \mathrm{~g} / \mathrm{L})$; it can be observed that xylanase production was major when CMC and urea concentrations were the minor, $1.6 \mathrm{~g} / \mathrm{L}$ and $0.32 \mathrm{~g} / \mathrm{L}$, respectively. Fig. 2B demonstrates the effects of CMC and peptone on xylanase production when the urea concentration was fixed at its middle level $(2 \mathrm{~g} / \mathrm{L})$; similarly, the maximum xylanase yield was reached at the lowest CMC concentration $(1.6 \mathrm{~g} / \mathrm{L})$; however, xylanase production increased when peptone levels were the highest (3-3.68 g/L). From Fig. $2 \mathrm{C}$ it can be concluded that xylanase production improved when urea and peptone levels were decreasing and increasing, respectively, while CMC concentration was fixed at its middle level (10 $\mathrm{g} / \mathrm{L})$.

CMC revealed to be the main positive medium component on xylanase production while the nitrogen sources, urea and peptone, were also statistically significant on the enzyme activity. The multiple regression analysis revealed a $R^{2}$ of 0.64 indicating that the model represents the data. Nevertheless, the statistically significant lack of fit (LOF) from ANOVA analysis indicated either that the model was not fitting all the design points well or the responses were highly repetitive around the center point (where the pure error was derived from). 

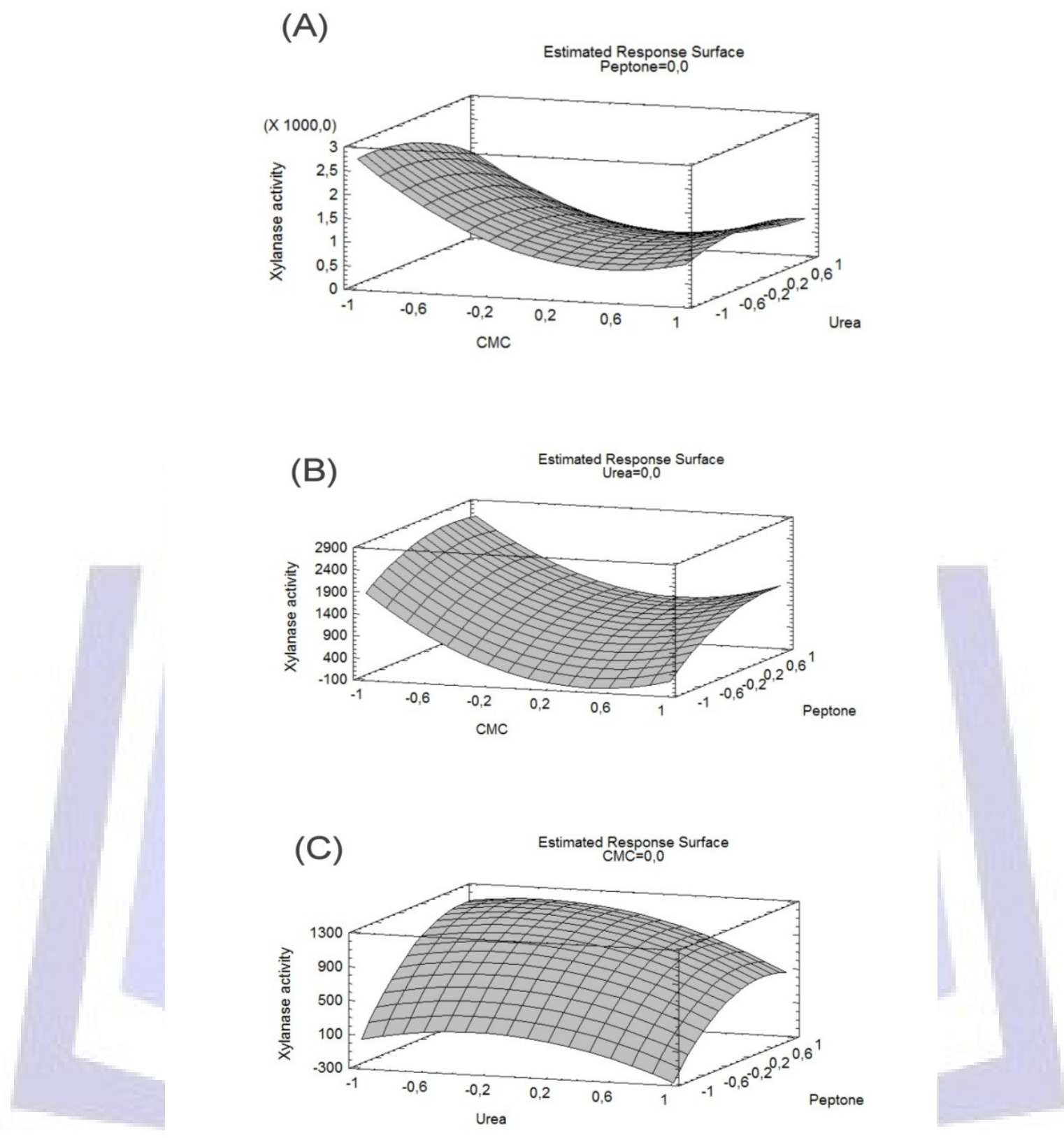

Figure 2. Three-dimensional response surface plots for xylanase production by I. lacteus BAFC 1168 strain $F$ showing the interactive effects of medium components. (A) CMC and urea when peptone is fixed on its middle level. (B) CMC and peptone when urea is fixed on its middle level and (C) urea and peptone when CMC is fixed on its middle level.

Despite the maximum predicted xylanase production was lower $(5.06 \mathrm{U} / \mathrm{mL})$ than the experimentally obtained $(7.04 \mathrm{U} / \mathrm{mL})$; it was decided to carry out the validation of the model and verify the reliability of the predicted result. Three experiments were conducted incubating I. lacteus BAFC 1168 strain F under the optimal predicted conditions: $1.6 \mathrm{~g} / \mathrm{L} \mathrm{CMC,} 0.84 \mathrm{~g} / \mathrm{L}$ urea and $2.5 \mathrm{~g} / \mathrm{L}$ peptone. The average xylanase yield obtained was $8.29 \mathrm{U} / \mathrm{mL}$, much higher than the predicted value. The xylanase activity reached at this point was 9.5 times higher than that obtained with the most effective culture medium in Plackett-Burman experiment.

\subsection{Optimum temperature and $\mathrm{pH}$}

Optimum temperature and $\mathrm{pH}$ for enhancing xylanase activity weredetermined in I. lacteus BAFC 1168 strain $\mathrm{F}$ supernatants employing a CCD. Center point values of temperature and $\mathrm{pH}$ were $50^{\circ} \mathrm{C}$ and 4.8 , respectively. In this $\mathrm{CCD}$, five levels $(-1.41,-1,0,1,1.41)$ of the factors were studied in twelve experiments (Table 6$)$. 
Table 6. Experimental design and results of the central composite design for temperature an $\mathrm{pH}$ on xylanase activity. Coded and real values (in parenthesis) of independent variables.

\begin{tabular}{|cccc|}
\hline Run & Temperature $\left({ }^{\circ} \mathbf{C}\right)$ & $\mathbf{p H}$ & $\begin{array}{c}\text { Xylanase activity } \\
(\mathbf{U} / \mathbf{m L})\end{array}$ \\
\hline 1 & $-1(35)$ & $1(5.8)$ & 7.317 \\
2 & $0(50)$ & $0(4.8)$ & 7.032 \\
3 & $1(65)$ & $-1(3.8)$ & 0.00 \\
4 & $0(50)$ & $-1.41(3.39)$ & 0.00 \\
5 & $0(50)$ & $1.41(6.21)$ & 7.139 \\
6 & $-1.41(28.78)$ & $0(4.8)$ & 5.020 \\
7 & $1(65)$ & $1(5.8)$ & 2.961 \\
8 & $-1(35)$ & $-1(3.8)$ & 0.611 \\
9 & $1.41(71.21)$ & $0(4.8)$ & 0.718 \\
10 & $0(50)$ & $0(4.8)$ & 7.062 \\
11 & $0(50)$ & $0(4.8)$ & 7.079 \\
12 & $0(50)$ & $0(4.8)$ & 7.114 \\
\hline
\end{tabular}

The results were then analyzed using the ANOVA (Table 7) and it was observed a statistically significance of all linear, quadratic and interactive effects of temperature and $\mathrm{pH}$ on xylanase activity.

Table 7.Results of the regression analysis of the central composite design for temperature and pH on xylanse activity.

\begin{tabular}{|ccccccc|}
\hline Variable & Sum of Squares & df & Mean Square & F value & P-value \\
\hline A & $3,08078 \mathrm{E} 7$ & 1 & $3,08078 \mathrm{E} 7$ & 18232,66 & 0,0000 \\
B & $9,81559 \mathrm{E} 7$ & 1 & $9,81559 \mathrm{E} 7$ & 58090,66 & 0,0000 \\
AA & $6,32293 \mathrm{E} 7$ & 1 & $6,32293 \mathrm{E} 7$ & 37420,41 & 0,0000 \\
AB & $7,19953 \mathrm{E} 6$ & 1 & $7,19953 \mathrm{E} 6$ & 4260,83 & 0,0000 \\
BB & $4,48712 \mathrm{E} 7$ & 1 & $4,48712 \mathrm{E} 7$ & 26555,69 & 0,0000 \\
Blocks & 1352,4 & 1 & 1352,4 & 0,80 & 0,4054 \\
LOF & $1,26461 \mathrm{E} 6$ & 11 & 114965, & 68,04 & 0,0000 \\
Pure error & 10138,2 & 6 & 1689,7 & & \\
Total (corr.) & $2,2785 \mathrm{E} 8$ & 23 & & & & \\
\hline
\end{tabular}

A: temperature; B: $\mathrm{pH}$; LOF: lack of fit; df: degree fo freedom.

The multiple regression analysis revealed a $R^{2}$ of 0.99 , indicating that the model represents the data adequately. Nevertheless, the statistically significant lack of fit from ANOVA analysis indicated that the responses were highly repetitive around the center point (where the pure error was derived from). To explain the effect of the temperature and $\mathrm{pH}$ on xylanase activity, the results obtained from the CCD were fitted to a second order polynomial equation [Eq. (4)]:

$\mathrm{Y}=7,072.1-1,387.62$ (temperature) $+2,476.84(\mathrm{pH})-2,222.57$ (temperature) $)^{2}$

- 948.653 (temperature) $(\mathrm{pH})-1,872.32(\mathrm{pH})^{2}$

where $Y$ is xylanase activity $(\mathrm{U} / \mathrm{mL})$. Fig. 3 shows the three dimensional plot resulting from the effects of temperature and $\mathrm{pH}$ on xylanase activity; it can be seen that the enzyme activity improved when the levels of the independent variables increased to midrange. 


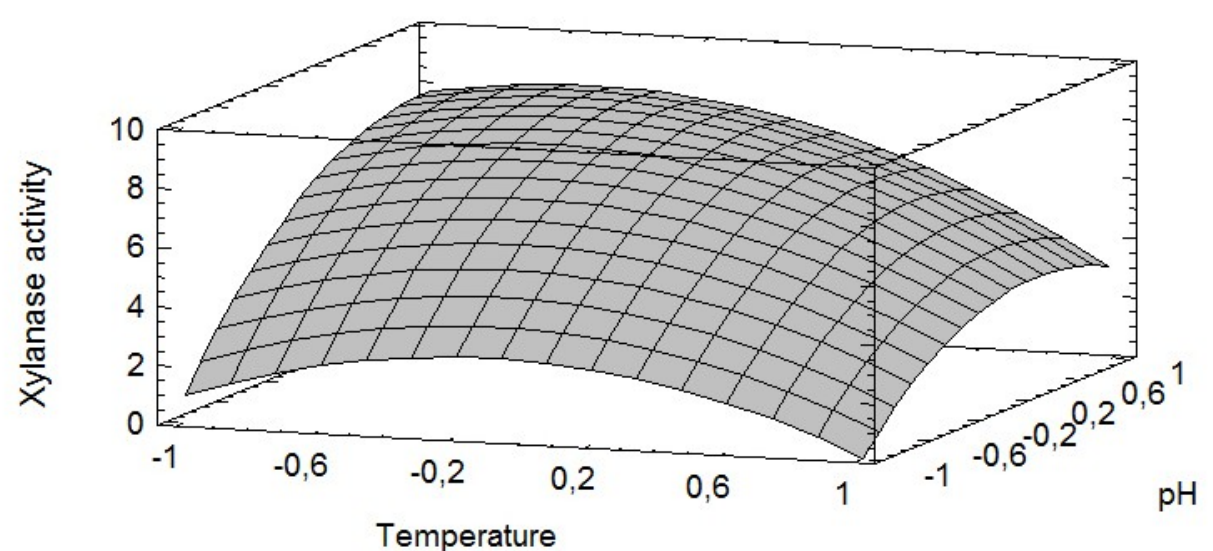

\section{Figure 3.Three-dimensional response surface plot for temperature and $\mathrm{pH}$ effects on xylanase activity from supernantants of $I$. lacteus BAFC 1168 strain $F$.}

The model predicted a maximum xylanase activity of $8.37 \mathrm{U} / \mathrm{mL}$ at $42.8^{\circ} \mathrm{C}$ and $\mathrm{pH} 5.6$. To validate the model it was carried out three experiments under these conditions resulting in $8.36 \mathrm{U} / \mathrm{mL}$ of xylanases. The excellent correlation between predicted and experimental values justifies the validity of the response model and the existence of an optimum point.

\section{DISCUSSION}

The effect of carbon and nitrogensources on enzymes production by fungi is of great importance [7]. However, in contrast to lignin-degrading enzymes, the information on hydrolases, specifically on xylanases produced by white rot Basidiomycetes is still scarce [8]. In this paper, the effects of six carbon sources, three nitrogen sources and a surfactant on xylanase production of the white rot fungus I. lacteus BAFC 1168 strain F using a PBD were screened and the most significant variables were identified. To our knowledge, many earlier studies on xylanase production were conducted by varying one factor at a time (OFAT); however, this is the first kind of work where many factors affecting xylanase production were studied simultaneously with the white rot fungus $l$. lacteus.

The wide variation in the responses according to the process conditions used in the PBD design indicated the strong influence exerted by independent variables on xylanase production and the importance on evaluating the media components for different fungi species [7]. From the analysis of variance, it can be concluded that two of the three nitrogen sources, peptone and urea, had significant positive effects on xylanase production, indicating an increase of enzyme activity when the variables levels were the higher. Among other nitrogen sources, the presence of peptone and urea were described as necessary medium components for xylanase production during the microbial fermentation [7, 18]. Regarding to carbon sources, in this study, CMC showed statistical significant and positive effect on xylanase production by $I$. lacteus BAFC 1168 strain F. Royer and Nakas [19] also demonstrated positive effects of cellulolytic substrates on xylanase production in studies with Trichoderma longibrachiatum. In contrast, lactose had significant and negative effect on enzyme production. In other fungi species lactose could not produce any significant production of xylanases [20]. The negative effect of lactose could own to its simple structure, playing a repressive role on xylanases synthesis or expression.Because of this, lactose was not included in the CCD experiment.

When the CCD was carried out, CMC revealed to be the main positive medium component on xylanase production while the nitrogen sources, urea and peptone, were also statistically significant on the enzyme activity. These results were in agreement with others previously reported by Kachlishvili et al. [21], who also described high xylanolytic activities in closely related fungal specimens such as Pleurotus dryinus, P. tuberregium, Lentinus edodes and Funalia trogii when were cultured with peptone. However, in the literature exists contradictory evidence on the nature and concentration effects of the carbon and nitrogen sources on xylanase production. Although the quadratic equation failed to predict the maximum xylanase production and keeping in mind a similar situation reported by Chaichanan et al. [22], we accomplished the validation of the model obtaining a remarkable xylanase production of $8.29 \mathrm{U} / \mathrm{mL}$ under the predicted conditions by the model ( $1.6 \mathrm{~g} / \mathrm{L} \mathrm{CMC}, 0.84 \mathrm{~g} / \mathrm{L}$ urea and $2.5 \mathrm{~g} / \mathrm{L}$ peptone).l. lacteus BAFC 1168 strain F could secrete an amount of xylanasesmuch higher than the predicted value and 9.5 times higher than inour most effective culture medium in Plackett-Burman experiment. The xylanase activity rechead at this point is similar with than obtained by Salmon et al. [23] using the Basidiomycete Ganoderma applanatum LPB MR-56. The ability of I. lacteus BAFC 1168 to produce xylanases is much higherthan the capacity of others Basidiomycetes; itcould produce a 36-foldactivity than the maximum xylanase production reported for another strain of Ganoderma applanatum by Dinnis et al. [24] and 66-fold higher than the observed in Phlebia rufa $(0.125 \mathrm{U} / \mathrm{mL})$, 83-fold higher than Trametes versicolor(nearly $0.075 \mathrm{U} / \mathrm{mL}$ ) and more than 100 fold than Bjerkandera adusta (less than $0.075 \mathrm{U} / \mathrm{mL}$ ) [24].

In addition to nutrient sources, xylanase activity is also strongly influenced by cultivation conditions as temperature and $\mathrm{pH}$ $[1,25]$. Hence, controlling these parameters and optimize them in the crude extract could achieve an optimal enzyme yield 
for a best process result and could serve to reduce the cost of enzyme purification. The literature discloses that most of the fungi produce higher xylanase activity when occurring temperatures below $50^{\circ} \mathrm{C}$ and exhibit optimum $\mathrm{pH}$ towards the acidic side, since 4 to 7 [1,26-28]. In this work,employing a CCD and its corresponding validation, we concluded thatoptimum temperature and $\mathrm{pH}$ for xylanase activity in $I$. lacteus BAFC 1168 strain $\mathrm{F}$ was $42.8^{\circ} \mathrm{C}$ and 5.6 , respectively. On the other side, there was an excellent correlation between the predicted xylanase activity $(8.37 \mathrm{U} / \mathrm{mL})$ and the experimental one $(8.36 \mathrm{U} / \mathrm{mL})$ demonstrating the existence of an optimum point. Studies carried out with I. lacteus [29] also conducted that the most suitable $\mathrm{pH}$ value for xylanase activity was within the acid region nearly $\mathrm{pH} 6$. However, its optimum temperature was nearly $60^{\circ} \mathrm{C}$.

Easy and cheap enzyme overproductionis important for efficient biotechnological applications [25]. According to the present results, I. lacteus BAFC 1168 strain F have a surprising potential for xylanase production when growing on CMC, peptone and urea and demonstrated the use of nonconventional, statistically based design techniques can serve as efficient tool in process development, where an analysis of the effect and interaction of many experimental factors are required. The enhancement of xylanase activity is a remarkable feature because some biotechnological application as an efficient saccharification process, high xylanase activity is necessary to degrade hemicellulose for increasing yields of fermenting 5 carbon sugars to obtain bioetanol. Nevertheless, it is still necessary to explore other variables to improve these levels of xylanasesand to obtain xylanases and celluloses in the same culture for optimizing the global bioethanol process.

\section{ACKNOWLEDGMENTS}

This study was supported by PICTO - UNaM 2011-0086, ANPCyT, Ministerio de Ciencia, Tecnología e InnovaciónProductiva, República Argentina. Authors wish to thank the financial support from Secretaría General de Ciencia y Tecnología de la Universidad Nacional de Misiones, through grants for innovation projects (16Q446).

GVD and EMG have fellowships from ConsejoNacional de InvestigacionesCientíficas y Técnicas (CONICET), Argentina.

Our thanks to the experts who have contributed towards development of the work.

\section{REFERENCES}

[1] Kulkarni, N., Shendye, A., and Rao, M. 1999 Molecular and biotechnological aspects of xylanases. FEMS Microbiol. Rev. 23, 411-456. doi: 10.1111/j.15746976.1999.tb00407.x

[2] Collins, T., Gerday, C., and Feller, G. 2005. Xylanases, xylanase families and extremophilic xylanases. FEMS Microbiol. Rev. 29, 3-23. doi: 10.1016/j.femsre.2004.06.005

[3] Damaso, M. C., Carvalho Andrade, C.,andPereira, N. Jr.2002. Production and properties of the cellulase-free xylanase from Thermomyces lanuginosus IOC-4145. Braz. J. Microbiol. 33, 333-338.10.1590/S151783822002000400011

[4] Min, B. J., Park, Y., Kang, S., Song, Y., Lee, J., Park, C., Kim, C., and Kim, S. 2007. Statistical optimization of medium components for the production of xylanase by Aspergillus niger KK2 in submerged cultivation. Biotechnol. Bioproc. 12, 302-307. doi: 10.1007/BF02931108

[5] Motta, F. L., Andrade, C., and Santana, M. 2013. A Review of Xylanase Production by the Fermentation of Xylan: Classification, Characterization and Applications, Sustainable Degradation of Lignocellulosic Biomass - Techniques, Applications and Commercialization. http://dx.doi.org/10.5772/53544

[6] Li ,Y., Lin, J., Meng, D., Lu, J., Gu, G., and Mao, Z. 2006 Effect of pH, cultivation time and substrate concentration on the endoxylanase production by Aspergillus awamori ZH-26 submerged fermentation using central composite rotary design. Food Technol. Biotech. 44, 473-477.

[7] Xu, Y., Li, Y., Xu, S., Liu, Y., Wang, X., and Tang, J. 2008. Improvement of xylanase production by Aspergillus niger $X Y-1$ using response surface methodology for optimizing the medium composition. J. Zhejiang Univ-Sc. B 9, 558566.doi: 10.1631/jzus.B0820038

[8] Kachlishvili, E., Khardziani, T., Metreveli, E., Kobakhidze, A., and Elisashvili, V. 2012. Screening of novel Basidiomycetes for the production of lignocellulolytic enzymes during fermentation of wood wastes. J.W.C.B.B. 1, 915. doi: $10.5147 /$ jpgs.2012.0078

[9] Cao, Y., Meng, D., Lu, J., and Long, J. 2008. Statistical optimization of xylanase production by Aspergillus niger AN13 under submerged fermentation using response surface methodology. Afr. J. Biotechnol.7, 631638.http://www.academicjournals.org/AJB

[10] Maciel, G. M., Vandenberghe, L., Fendrich, R., Della, B., Haminiuk, C.,and Soccol, C. 2009. Study of some parameters which affect xylanase production: strain selection, enzyme extraction optimization, and influence of drying conditions. Biotechnol. Bioproc . 14, 748-755. DOI/10.1007/s12257-009-0053-8

[11] Irfam, M., Nadeem, M., and Syed, Q. 2014. One-factor-at-a-time (OFAT) optimization of xylanase production from Trichoderma viridae-IR05 in solid-state fermentation. J.R.R.A.S. 7, 317-326. 
[12] Chebez, J. C. 2005. Guía de las Reservas Naturales de la Argentina 3 Nordeste, 1st edN., Albatros, Buenos Aires, Argentina pp. 16-18.

[13] Plackett, R. and Burman, J. 1946. The design of optimum multifactorial experiments. Biometrika 33, 305-325.doi: 10.1093/biomet/33.2.305

[14] Box, G. E. and Wilson, K. 1951. On the experimental attainment of optimum conditions. J. Roy. Stat. Soc. B. 13, $1-$ 45.doi: 10.1007/978-1-4612-4380-9 23

[15] Bailey, M. J., Biely, P., and Poutanen, K. 1992. Interlaboratory testing methods for assays of xylanase activity. J. Biotechnol. 23, 257-270. doi: 10.1016/0168-1656(92)90074-J

[16] Miller, G. 1959. Use of dinitrosalicylic acid reagent for determination of reducing sugars. Anal. Chem. 31, 426-428.doi: 10.1021/ac60147a030

[17] Mesa, L., González, E., Cara, C., Ruiz, E., Castro, E., and Mussatto, S. 2010.An approach to optimization of enzymatic hydrolysis from sugarcane bagasse base don organosolv pretreatment. J. Chem. Technol. Biotechnol. 85, 1092-1098.doi: 10-1002/jctb.2404

[18] Bakri, Y., Jacques, P., and Thonart, P.2003. Xylanase production by Penicillium canescens 10-10c in solid-state fermentation. Appl Biochem Biotech 108, 737-748.doi: 10.1385/ABAB:108:1-3:737

[19] Royer, J. C. and Nakas, J. 1989. Xylanase production by Trichoderma longibrachiatum. Enzyme Microb. Technol. 11, 405-410. doi: 10.1016/0141-0229(89)90134-8

[20] Tallapragada, P. and Venkatesh, K. 2011. Isolation, identification and optimization of xylanase enzyme produced by Aspergillus nigerunder submerged fermentation. J. Microbiol. Biotechon. Research 1, 137-147.

[21] Kachlishvili, E., Penninckx, M., Tsiklauri, N., and Elisashvili, V. 2006. Effect of nitrogen sources on lignocellulolytic enzyme production by white rot basidiomycetes on solid-state cultivation. World J. Microb.Biot. 22, 391-397. doi: $10.1007 / \mathrm{s} 11274-005-9046-8$

[22] Chaichanan, J., Wiyakrutta, S., Pongharangkul, T., Isarangkul, D., and Meevootisom, V. 2014. Optimization of zomarin production by an endophytic fungus, Xylaria sp. Acra L38. Braz. J. Microbiol.45, 287-293.doi: $10.1590 / \mathrm{S} 1517-83822014000100042$

[23] Salmon, D. N., Spier, M., Soccol, C., Vandenberghe, L., Weingartner Montibeller, V., Bier, M., and Faraco, V. 2014. Analysis of inducers of xylanase and cellulose activities production by Ganoderma applanatum LPB MR-56. Fungal Biol. 118, 655-622. doi: 10.1016/j.funbio.2014.04.003

[24] Dinnis, M. J., Bezerr, R., Nunes, F., Dias, A., Guedes, C., Ferreir, L., Cone, J., Marques, G., Barros, A., andRodrigues, M. 2009. Modification of wheat straw lignin by solid state fermentation with white- rot fungi. Bioresource Technol. 100, 4829-4835. doi: 10.1016/j.biortech.2009.04.036

[25] Dhiman , S.S., Sharma, J. and Battan, B. 2008. Industrial applications and future prospects of microbial xylanases: a review. Bioresources 3, 1377-1402.

[26] Subramaniyan, S. and Prema, P. 2002.Biotechnological of microbial xylanases: enzimology, molecular biology and application. Crit. Rev.Biotechnol. 22, 33-46. doi: 10.1080/07388550290789450

[27] Cuyvers, S., Dornez, E., Moers, K., Pollet, A., Delcour, J., andCourtin, C. 2011. Evaluation of the xylan breakdown potential of eight mesophilic endoxylanases. Enzyme Microb. Tech. 49, 305-311. doi: 10.1016/j.enzmictec.2011.05.005

[28] Päes, G., Berrin, J., and Beaugrand, J. 2012. GH11 xylanases: structure/function/properties relationships and applications. Biotechnol. Adv. 30, 564-592. doi: 10.1016/j.biotechadv.2011.10.003

[29] Kanda, T., Amano, Y.,and Nisizawa, K. 1985. Purification and properties of two endo-1,4- $\beta$-xylanases from Irpex lacteus (Polyporus tulipiferae). J. Biochem. 98, 1545-1554.

\section{Author' biography with Photo}

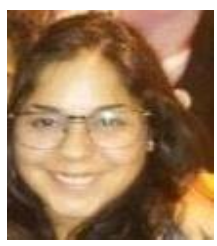

Gabriela VerónicaDíaz is graduated in Genetics from Universidad Nacional de Misiones. She is student of PhD in Applied Science in Universidad Nacional de Misiones. Her current interests are on the topics of enzymatic fermentation and biotechnological applications for xylanolytic enzymes. 